PACS: $29.17 .+\mathrm{w} ;$ 41.75.Lx

\title{
OCCURRENCE OF ACCELERATING FIELD, FORMATION AND DYNAMICS OF RELATIVISTIC ELECTRON BEAM NEAR JUPITER
}

\author{
V.I. Maslov ${ }^{1,2}$, I.P. Levchuk ${ }^{1}$, S. Nikonova ${ }^{2}$, I.N. Onishchenko ${ }^{1}$ \\ ${ }^{I} N S C$ "Kharkiv Institute of Physics and Technology" NASU \\ Kharkiv, 61108, st. Akamemicheskaya 1, Ukraine \\ ${ }^{2}$ V.N. Karazin Kharkiv National University \\ 4 Svobody Sq., Kharkiv, 61022, Ukraine \\ e-mail:vmaslov@kipt.kharkov.ua \\ Received April 6, 2018
}

\begin{abstract}
The possible dynamics of the electron beam, formed in the vicinity of Io, the natural satellite of Jupiter, and injected toward Jupiter, has been investigated analytically. When a beam penetrates the Jupiter plasma to a certain depth, the beam-plasma instability can be developed. In this case, the distribution function of electrons is expanded additionally by excited oscillations. These electrons, when their energy is of order of a required certain value, cause UV polar light. For closing of a current, the formation of a double electric layer is necessary. The necessary parameters and conditions for the formation of a double layer with a large jump of an electric potential at a certain height have been formulated, its properties, stability, behavior over time and beam reflection in its field for closing of a current have been described. Reflection of the beam can lead to its vortex dynamics.

KEYWORDS: electron beam dynamics, polar light of Jupiter, a double electric layer, beam plasma instability

\section{ВИНИКНЕННЯ ПРИСКОРЮЮЧОГО ПОЛЯ, ФОРМУВАННЯ І ДИНАМІКА РЕЛЯТИВІСТСЬКОГО ЕЛЕКТРОННОГО ПУЧКА В ОКОЛИЦІ ЮПТЕРА \\ В.І. Маслов ${ }^{1,2}$, І.П. Левчук ${ }^{1}$, С. Ніконова ${ }^{2}$, І.М. Онищенко \\ ${ }^{1}$ Національний Науковий Центр «Харківський фізико-технічний інститут» 61108, Харків, Академічна, 1 \\ ${ }^{2}$ Харківський начіональний університет імені В.Н. Каразіна \\ пл. Свободи 4, Харків, 61022, Україна}

Аналітично досліджено можливу динаміку електронного пучка, який формується в околиці Іо - природного супутника Юпітера та інжектується в напрямку Юпітера. При проникненні пучка в плазму Юпітера на певну глибину може розвинутися пучково-плазмова нестійкість. При цьому коливання, які збуджуються, додатково розмивають функцію розподілу електронів. Ці електрони, якщо їх енергія порядку необхідної певної величини, викликають УФ полярне сяйво. Для замикання струму необхідно формування подвійного електричного шару. Сформульовано необхідні параметри і умови формування на деякій висоті подвійного шару з великим стрибком електричного потенціалу, описані його властивості, стійкість, поведінку в часі і відбиття пучка в його полі для замикання струму. Відбиття пучка може призвести до його вихрової динаміки.

КЛЮЧОВІ СЛОВА: динаміка електронного пучка, полярне сяйво Юпітера, подвійний електричний шар, пучковоплазмова нестійкість

\section{ВОЗНИКНОВЕНИЕ УСКОРЯЮЩЕГО ПОЛЯ, ФОРМИРОВАНИЕ И ДИНАМИКА РЕЛЯТИВИСТСКОГО ЭЛЕКТРОННОГО ПУЧКА В ОКРЕСТНОСТИ ЮПИТЕРА В.И. Маслов ${ }^{1,2}$, И.П. Левчук ${ }^{1}$ С. Никонова ${ }^{2}$, И.Н. Онищенко ${ }^{1}$ \\ ${ }^{1}$ Национальный Научный Центр «Харьковский физико-технический институт» 61108, Харьков, Академическая, 1 \\ ${ }^{2}$ Харьковский национальный университет имени В.Н. Каразина пл. Свободы 4, Харьков, 61022, Украина}

Аналитически исследована возможная динамика электронного пучка, формируемого в окрестности Ио - естественного спутника Юпитера и инжектируемого в сторону Юпитера. При проникновении пучка в плазму Юпитера на определенную глубину может развиться пучково-плазменная неустойчивость. При этом возбуждаемые колебания дополнительно размывают функцию распределения электронов. Эти электроны, если их энергия порядка определенной величины, вызывают УФ полярное сияние. Для замыкания тока необходимо формирование двойного электрического слоя. Сформулированы необходимые параметры и условия формирования на некоторой высоте двойного слоя с большим скачком электрического потенциала, описаны его свойства, устойчивость, поведение во времени и отражение пучка в его поле для замыкания тока. Отражение пучка может привести к его вихревой динамике.

КЛЮЧЕВЫЕ СЛОВА: динамика электронного пучка, полярное сияние Юпитера, двойной электрический слой, пучковоплазменная неустойчивость

In this paper, the possible dynamics of an electron beam in the vicinity of Jupiter, which leads to polar light of Jupiter [1-10] and which according to model [11] is accelerated in the Io vicinity, has been investigated. Electron bunches move along a magnetic tube from Io to Jupiter. Since the magnetic field lines of Jupiter meet at its poles, the beam is focused while moving toward Jupiter, and the density of the beam electrons increases. When the beam penetrates into the plasma to a certain depth, the beam-plasma instability (BPI) develops. In this case, the excited 
oscillations expand the electron distribution function. Thus, from their energy distribution function, a tail grows, which determines the observed aurora in the UV range.

Since BPI in an inhomogeneous plasma develops locally, it can at some height lead to the formation of a double layer (DL). The conditions for the formation of this DL have been formulated, its properties have been obtained, the dynamics of plasma particles and the reflection of the beam back in its field have been described. After reflection from Jupiter upper ionosphere electron bunches change the direction of motion (see [12]).

The effect of the space charge of a decelerated beam and its collision with particles of partially ionized plasma lead to a gradual expansion of the decelerating beam. Thus, the reflected beam moves back on a larger radius, leading to vortex dynamics.

The aim of the paper is the formulation and analytical description of the model of the possible dynamics of the electron beam, formed in the vicinity of Io - the natural satellite of Jupiter and injected towards Jupiter, which leads to polar light of Jupiter.

\section{BEAM-PLASMA INSTABILITY}

The energy of the beam electrons is too high to cause UV auroras. However, the BPI [3, 4], caused by them, can form the tail of the electron distribution function up to the UV range (Fig. 1).

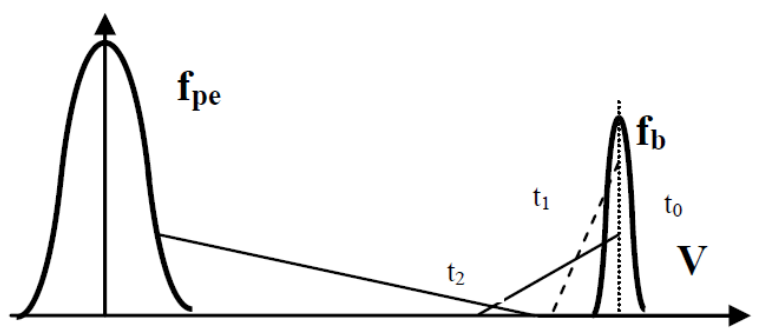

Fig. 1. The distribution functions of the beam and plasma electrons formed at $t_{2}>t_{1}>t_{0}$ as a result of the possible electron beam interaction with the Jovian plasma

Thus, when a beam penetrates into the plasma to such depth that the plasma electron density $\mathrm{n}_{0 \mathrm{e}}$ becomes large and at a significant focusing of the electron beam, so that its density $n_{b}$ becomes larger than some threshold, the BPI can be developed $[13,14]$. Growth rate $\gamma_{b}$ of BPI equals

at a rapid stage of evolution and

$$
\gamma_{\mathrm{bq}}=\frac{\sqrt{3}}{2^{4 / 3}}\left(\frac{\mathrm{n}_{\mathrm{b}}}{\mathrm{n}_{0 \mathrm{e}}}\right)^{1 / 3} \omega_{\mathrm{pe}} \propto \mathrm{n}_{\mathrm{b}}^{1 / 3} \mathrm{n}_{\mathrm{oe}}^{1 / 6} .
$$

$$
\gamma_{\mathrm{bs}} \approx\left(\frac{\mathrm{n}_{\mathrm{b}}}{\mathrm{n}_{0 \mathrm{e}}}\right) \omega_{\mathrm{pe}}
$$

at a slow stage of evolution. As growth rate $\gamma_{b}$ is proportional to $n_{b}$ and to the plasma electron density, the instability develops at a certain height, where the electron density $\mathrm{n}_{0 \mathrm{e}}$ of the inhomogeneous plasma is large.

\section{PROPERTIES OF DOUBLE ELECTRIC LAYER, REFLECTING ELECTRON BEAM}

Since the current must be closed, the beam at some height should be reflected and go back. Let us consider a possible mechanism of beam reflection. The reflection mechanism from the ionosphere is associated with the formation of double layers at entering the bunches of fast electrons with density $\mathrm{n}_{\mathrm{b}} \approx 10^{4} \mathrm{~cm}^{-3}$ in the ionosphere at heights where the density of ionosphere ions $n_{i}$ approximately equals to $n_{b}[12]$.

1D numerical simulation [15] has shown that at injection of an electron beam into a plasma, DL can be formed. Let us show that at an electron beam injection from a source into the plasma with a density comparable to the plasma density $\mathrm{n}_{\mathrm{b}}=\mathrm{n}_{\mathrm{i}}$, the formation of DL is possible, which reflects the beam from the plasma [16].

Let us study the phenomena, accompanying injection from a certain time from a source (for example, from a natural satellite of Jupiter) to Jupiter plasma an electron beam with a density $\mathrm{n}_{\mathrm{b}}$ which is comparable to the plasma density, $n_{\mathrm{i}}$.

At a beam injection from an isolated source into the plasma, the plasma electrons are accelerated towards the source of the electron beam in the field of the potential drop arising between the source and the beam. At $n_{b} \approx n_{i}$, the plasma electron current to the source is small compared to the injected beam current, $\mathrm{j}_{\mathrm{b}}=\mathrm{n}_{\mathrm{b}} \mathrm{V}_{\mathrm{b}}$. The resulting reverse plasma current is small, since plasma electrons close to the boundary are accelerated insignificantly, and those plasma electrons, located in the interior of the plasma near the beam reflection region, are accelerated to velocities reaching the injection velocity, but their density becomes much smaller than the beam density. Thus, the reverse plasma current does not compensate the accumulation of a positive source charge. Therefore, the potential drop reaches the kinetic energy of the beam. The beam returns to the source, being reflected from the potential jump and compensating the accumulation 
of a positive charge on the source. Then the potential can separate from the source and move inside the plasma with a certain velocity $\mathrm{V}_{\mathrm{dl}}$. So DL is formed (the potential jump from $\varphi_{\mathrm{o}}=\varphi(\mathrm{x}=0)$ on the injection boundary to zero on $\Delta \mathrm{x}$ ).

Let us consider DL that the perturbation of the ion density in its field is insignificant

$$
\left|\delta n_{\mathrm{i}}\right|=\mathrm{n}_{\mathrm{i}} \frac{\mathrm{e} \phi_{\mathrm{o}}}{\mathrm{m}_{\mathrm{i}} \mathrm{V}_{\mathrm{dl}}^{2}} \ll<\mathrm{n}_{\mathrm{i}} .
$$

The appearance of charge separation in the form of two oppositely charged regions is necessary for the DL formation. For an electron DL formation at an electron beam injection into the plasma, two groups of injected electrons are necessary for this charge separation. The second group, in contrast to the beam, should be slow. The second group cannot be plasma electrons that fly into the DL region and are accelerated in its field to velocity $\left(\mathrm{V}_{\mathrm{dl}}{ }^{2}+2 \mathrm{e} \varphi_{\mathrm{o}} / \mathrm{m}\right)^{1 / 2}$, since their density deceases in DL to a small value $\mathrm{n}\left(\mathrm{V}_{\mathrm{th}} / \mathrm{V}_{\mathrm{b}}\right)$. $\mathrm{V}_{\mathrm{th}}$ is the thermal velocity of the plasma electrons. A slow group is formed by trapping a part of the plasma electrons by DL, which is rapidly formed, or it is injected together with a fast beam. First we consider the case of injection of two groups.

Let us consider a semi-infinite plasma, $\mathrm{x}>0$, into which, high-energy, $\mathrm{V}_{\mathrm{b}}>>\mathrm{V}_{\text {th }}, \mathrm{V}_{\text {thb }}$, and slow, $\mathrm{V}_{\mathrm{sl}}<\mathrm{V}_{\text {tho }}<<\mathrm{V}_{\mathrm{b}}$, beams are injected with densities $n_{b}$ and $n_{0} . V_{\text {thb }}=\left(T_{b} / m\right)^{1 / 2}, V_{\text {tho }}=\left(T_{0} / m\right)^{1 / 2}-$ thermal velocities of electron beams. Since the distribution function of the slow group of electrons after reflection from the DL becomes symmetric with respect to the velocity of the DL $\mathrm{V}_{\mathrm{dl}}$, the average velocity of the slow group $\mathrm{V}_{\mathrm{sl}}$ can be set equal to $\mathrm{V}_{\mathrm{sl}}=\mathrm{V}_{\mathrm{dl}}<<\mathrm{c}$.

First, we find from the kinetic equation and the equations of the balance of energy and momentum fluxes the stationary characteristics of Dl.

Electrons move along trajectories

$$
\mathrm{mc}^{2}(\gamma-1)-\mathrm{e} \varphi=\text { const } .
$$

In this case, plasma electrons in the DL rest system are accelerated in its field from $-\mathrm{V}_{\mathrm{dl}}$ to $-\mathrm{c}\left(1-\gamma_{\mathrm{o}}{ }^{-2}\right)^{1 / 2}, \gamma_{\mathrm{o}}=\left[1-\left(\mathrm{V}_{\mathrm{b}^{-}}\right.\right.$ $\left.\left.\mathrm{V}_{\mathrm{dl}}+\mathrm{V}_{\text {thb }}\right)^{2} / \mathrm{c}^{2}\right]^{-1 / 2}$. At the same time, their density changes as

$$
\mathrm{n}_{\mathrm{e}}(\mathrm{x})=\mathrm{n}_{\mathrm{e}}\left(\frac{\mathrm{V}_{\mathrm{dl}}}{\mathrm{c}}\right)\left\{1-\left[\left(1-\frac{\mathrm{V}_{\mathrm{dl}}^{2}}{\mathrm{c}^{2}}\right)^{-\frac{1}{2}}+\left(\gamma_{0}-1\right) \frac{\varphi}{\varphi_{0}}\right]^{-2}\right\}^{-\frac{1}{2}},
$$

decreasing from $n_{e}(\varphi=0)=n_{e}$ to $n_{e}\left(\varphi=\varphi_{0}\right)=n_{e}\left(V_{d l} / c\right)\left(1-\gamma_{o}^{-2}\right)^{-1 / 2}$. Dynamics of the slow electron group is nonrelativistic, and their density varies according to

$$
\mathrm{n}_{0}(\mathrm{x})=\mathrm{n}_{0} \exp \left[\frac{\mathrm{e}\left(\varphi-\varphi_{0}\right)}{\mathrm{T}_{0}}\right] .
$$

One can see from (6) that the density of the slow group decreases exponentially and forms a positive charge at $\varphi_{\mathrm{a}}<\varphi<\varphi_{0}$. Densities of fast beam

$$
\mathrm{n}_{\mathrm{b}}(\mathrm{z})=\mathrm{n}_{\mathrm{b}} \sqrt{1-\frac{1}{\gamma_{0}^{2}}}\left[1-\left(1+\frac{\mathrm{e} \varphi}{\mathrm{mc}^{2}}\right)^{-2}\right]^{-\frac{1}{2}} .
$$

and of the plasma electrons (5) increase in a power law, which leads to a negative charge at $0<\varphi<\varphi_{a} \cdot \varphi_{a}$ is determined from $\delta \mathrm{n}\left(\varphi_{\mathrm{a}}\right)=0$

$$
\varphi_{\mathrm{a}}=\frac{\varphi_{0}}{\gamma_{0}-1}\left\{\sqrt{\frac{\gamma_{0}+1}{2}}-1\right\} .
$$

One can derive that at $\varphi_{\mathrm{c}}=\varphi_{\mathrm{o}}\left(2 \mathrm{~V}_{\mathrm{bth}} / \mathrm{c}\right) \gamma_{\mathrm{o}}^{2}$ the beam reflection begins. As a result, quasineutrality is restored after DL.

Since the nonresonant beam electrons, passing through DL, penetrate into the plasma, where they are decelerated, their density increases. Therefore, the quasineutrality condition behind DL (for $x>>\Delta x$ ) requires that $V_{\mathrm{dl}}$ be less than the thermal velocity of the plasma electrons $\mathrm{V}_{\mathrm{dl}}<\mathrm{V}_{\text {th }}$, and the density of the beam electrons, penetrating through the DL, should be small $\mathrm{n}_{\mathrm{bo}}<<\mathrm{n}_{\mathrm{e}}$. Consequently

$$
\varphi_{0} \approx \frac{\mathrm{mc}^{2}}{\mathrm{e}}\left(\gamma_{0}-1\right) .
$$

All electrons transmit a momentum to DL. The fluxes of momenta transmitted to the DL by beam electrons, passing through DL, by electrons of the slow group and by beam, which are reflected from DL, are equal to $\mathrm{cmn}_{\mathrm{e}} \mathrm{V}_{\mathrm{dl}}\left(\gamma_{\mathrm{o}}^{2}-1\right)^{1 / 2}, \mathrm{n}_{\mathrm{bo}} \mathrm{mc}^{2}\left(\gamma_{\mathrm{o}}^{2}-1\right) / \gamma_{\mathrm{o}}, \mathrm{n}_{\mathrm{o}} \mathrm{T}_{\mathrm{o}}, 2\left(\mathrm{n}_{\mathrm{b}}-\mathrm{n}_{\mathrm{bo}}\right) \mathrm{mc}^{2}\left(\gamma_{\mathrm{o}}^{2}-1\right) / \gamma_{\mathrm{o}}{ }^{2}$. In DL field only ions receive a momentum whose flux is equal to $n_{i} e \varphi_{0}$. Electrons and plasma ions take energy from DL, whose fluxes are $n_{e} e \varphi_{o} V_{d l}, n_{i} e \varphi_{o} V_{d l}$. The electrons of the beam and the slow group lose energy when interacting with DL. The energy fluxes, which are transmitted to DL by slow group, which are reflected from DL, and by passing through DL beam electrons, are equal to $V_{\mathrm{dl}} \mathrm{n}_{\mathrm{o}} \mathrm{T}_{\mathrm{o}},\left(\mathrm{n}_{\mathrm{b}^{-}}\right.$ $\left.\mathrm{n}_{\mathrm{bo}}\right) \mathrm{mc}^{2} 2 \mathrm{~V}_{\mathrm{dl}}\left(\gamma_{\mathrm{o}}^{2}-1\right) / \gamma, \mathrm{n}_{\mathrm{bo}} \mathrm{e} \varphi_{\mathrm{o}} \mathrm{c}\left(1-\gamma_{\mathrm{o}}^{-2}\right)^{1 / 2}$. Using the equations for the balance of the energy and momentum fluxes, as well as the quasi-neutrality condition on the beam injection boundary, one can obtain: 


$$
\begin{aligned}
& \frac{\mathrm{V}_{\mathrm{dl}}}{\mathrm{c}}= \frac{\mathrm{n}_{\mathrm{b} 0}}{\mathrm{n}_{\mathrm{e}}} \sqrt{1-\frac{1}{\gamma_{0}^{2}}}<<1, \\
& \mathrm{n}_{\mathrm{b} 0}=\left[\frac{\mathrm{n}_{\mathrm{i}}}{2}-\mathrm{n}_{0} \frac{\mathrm{T}_{0}}{2 \mathrm{e} \varphi_{0}}\right] \frac{\gamma_{0}}{\gamma_{0}+1}, \\
& \mathrm{n}_{0}=\left[1+\frac{\mathrm{T}_{0}}{\mathrm{e} \varphi_{0}} \frac{\gamma_{0}}{\gamma_{0}+1}\right] \frac{\mathrm{n}_{\mathrm{i}}}{\gamma_{0}+1} .
\end{aligned}
$$

Let us find the DL profile and estimate its width. From (6) we find that in the reflection region of the slow group $\delta \mathrm{n}\left(\varphi_{\mathrm{b}}\right) \approx-\mathrm{n}_{\mathrm{o}}, \varphi_{\mathrm{b}}$ is determined from $\mathrm{dn}\left(\varphi_{\mathrm{b}}\right) / \mathrm{d} \varphi=0$ and equal to $\varphi_{\mathrm{b}} / \varphi_{\mathrm{o}}=1-\mathrm{T}_{\mathrm{o}} / \mathrm{e} \varphi_{\mathrm{o}}$. I.e. in a region, where the perturbation of the charge density is determined by the change in the density of the slow group, the potential drop is insignificant. In a region, where the perturbation of the charge density is determined by the change in the density of a fast beam upon its deceleration, $\delta$ increases to $\varphi=\varphi_{\mathrm{dl}}$. The maximum $\delta \mathrm{n}$ is reached in the region of strong deceleration of the beam and it is equal to $\delta \mathrm{n}\left(\varphi_{\mathrm{dl}}\right)=\mathrm{n}_{\mathrm{b}}\left(2 \mathrm{~V}_{\mathrm{b}} / \mathrm{V}_{\mathrm{thb}}\right)^{1 / 2} / \gamma^{3 / 2}$. In neglecting small intervals (widths of $\varphi_{\mathrm{c}}$ and $\left.\varphi_{\mathrm{o}}-\varphi_{\mathrm{b}}\right)$ near $\varphi=0$ and $\varphi=\varphi_{\mathrm{o}}$, we obtain

From here

$$
\frac{(\partial \varphi / \partial x)^{2}}{3 \pi \mathrm{e}}=\int \mathrm{d} \varphi \delta \mathrm{n}=\mathrm{n}_{\mathrm{i}} \sqrt{\varphi \varphi_{0}}\left[\sqrt{\frac{\left(\gamma_{0}+1\right) \varphi / \varphi_{0}+2}{\left(\gamma_{0}+1\right)}}-\sqrt{\frac{\varphi}{\varphi_{0}}}\right] .
$$

Let us determine the width D:

$$
\frac{\varphi}{\varphi_{0}}=1-\frac{\mathrm{x} \omega_{\mathrm{p}} \sqrt{2}}{\mathrm{c} \gamma_{0}}
$$

$$
\Delta \mathrm{x}=\frac{\varphi_{0}}{\left.(\partial \varphi / \partial \mathrm{x})\right|_{\varphi=\varphi_{\mathrm{a}}}} \approx \frac{\mathrm{c}}{4 \mathrm{e}} \sqrt{\frac{2 \mathrm{~m}}{\pi \mathrm{n}_{\mathrm{i}}}} \frac{\left(\gamma_{0}-1\right)}{\sqrt{1-\sqrt{\frac{2}{\gamma_{0}+1}}}} .
$$

And at $\gamma_{\mathrm{o}}>>1 \Delta \mathrm{x}=\left(\mathrm{c} / \omega_{\mathrm{p}} \sqrt{2}\right) \gamma_{\mathrm{o}}, \omega_{\mathrm{p}}=\left(4 \pi \mathrm{n}_{\mathrm{i}} \mathrm{e}^{2} / \mathrm{m}\right)^{1 / 2}$.

We now consider the case of injection from a source into the plasma of only a fast beam. It follows from (13) that for $\gamma_{\mathrm{o}} \gg>1$ the double layer is formed during the time $\gamma_{\mathrm{o}} / \omega_{\mathrm{p}} \sqrt{2}$. And the response time of plasma electrons to the formed field, according to (11), is equal to

$$
\mathrm{t}_{0}=\frac{\gamma_{0}}{\omega_{\mathrm{p}} \sqrt{2}} \sqrt[4]{\frac{\phi_{0}}{\phi_{0}(\mathrm{t})}} \cdot \mathrm{t}_{\mathrm{o}}=\left(\gamma_{\mathrm{o}} / \omega_{\mathrm{p}} \sqrt{2}\right)\left(\phi_{\mathrm{o}} / \phi_{\mathrm{o}}(\mathrm{t})\right)^{1 / 4} .
$$

Hence it can be concluded that during the formation time DL the plasma electrons do not have time to react to the formed field. Before the beam is reflected and reaches the boundary, the plasma electrons close to it are thrown out to the source under the action of the arisen field. When the plasma density is reached, which satisfies the inequality $\mathrm{n}_{\mathrm{e}}(\mathrm{t})<\mathrm{n}_{\mathrm{i}}-\mathrm{n}_{\mathrm{b}}$, the self-consistent potential ceases to be monotonic. The potential grows inside the plasma from $\varphi_{\mathrm{o}}(\mathrm{t})$ to $\varphi_{1}(\mathrm{t})$. Further, inside the plasma the potential falls sharply from $\varphi_{1}(\mathrm{t})$ to zero. This distribution of the potential keeps from the ejection to the source of the part of the plasma electrons which were during the DL formation in its vicinity, to neutralize, together with the charge beam, plasma ions. These trapped plasma electrons form the slow group necessary for DL formation. After completion of DL formation, the plasma electrons, fly into DL region, are accelerated toward the beam.

Let us consider the stability of the relative motion of electron fluxes. From (4), (5) - (7) we have an equation describing the excitation of HF perturbations in the DL neighborhood:

$$
1-\frac{\alpha}{z^{2}}-\frac{(1-\alpha)}{2 \gamma_{0}^{3}}\left[(z-y)^{-2}+(z+y)^{-2}\right]=0 .
$$

$\alpha=n_{\mathrm{o}} / \mathrm{n}_{\mathrm{i}}, \mathrm{z}=\omega / \omega_{\mathrm{p}}, \mathrm{y}=\mathrm{k}_{\mathrm{b}} / \omega_{\mathrm{p}}$. It follows from (15) that HF noise is generated in the DL region due to the development of BPI. They lead, as noted above, to the spreading of the electron distribution function. In [15, 17], noise does not lead to a significant DL destruction due to: spreading of the electron distribution function; inhomogeneity of the potential, which ensures the violation of the wave-particle resonance condition and the large relative noise velocity and DL.

Since DL moves slowly inside the plasma, the density of trapped electrons $\mathrm{n}_{\mathrm{o}}$ decreases in the case of nonmonotonic DL, since the localization region of these electrons increases. The study of the stability of electron fluxes with respect to LF perturbations on the basis of equation

$$
1+\frac{\alpha}{\left(\mathrm{kd}_{0}\right)^{2}}-\frac{(1-\alpha)}{2 \gamma_{0}^{3}}\left[(\mathrm{z}-\mathrm{y})^{-2}+(\mathrm{z}+\mathrm{y})^{-2}\right]=0
$$

$\mathrm{d}_{\mathrm{o}}=\left(\mathrm{T}_{\mathrm{o}} / 4 \pi \mathrm{n}_{\mathrm{e}}{ }^{2}\right)^{1 / 2}$, shows that when the density of the trapped electrons falls below the critical value 


$$
\frac{\left(\mathrm{V}_{\text {tho }} / \mathrm{V}_{\mathrm{b}}\right)^{2}}{\gamma_{0}^{3}}>\alpha+\left(\mathrm{kd}_{0}\right)^{2}
$$

DL becomes unstable with respect to perturbations with the phase velocity equal to $\mathrm{V}_{\mathrm{dl}}$. Numerical simulation [17] has shown that in this case DL, which has shifted into the plasma, decays, forming a vortex in the electron phase space and a new DL appears on the boundary.

It was shown in [16] that DL can be formed in a beam-plasma system only, as observed, when $\mathrm{n}_{\mathrm{b}} \approx \mathrm{n}_{\mathrm{i}}$.

Thus, it has been shown that injection from a source into a plasma of an electron beam with $\mathrm{n}_{\mathrm{b}} \approx \mathrm{n}_{\mathrm{i}}$ can lead to the DL formation.

DL reflects the beam back, so the electron velocity distribution function at the injection boundary has three maxima, which was observed in [15].

If the beam and plasma parameters differ from those, necessary for the formation of a monotonous DL, then within some limits of such a deviation near the DL in its low potential region a potential dip can be formed. The depth of the dip is self-consistently adjusted to the parameters of the beam and plasma, facilitating the DL formation and the beam reflection. In particular, the potential well, reducing the fraction of the beam passing to the low potential region, ensures quasi-neutrality in this region. The potential well in the region of low potential of DL is also formed due to 3D beam dynamics and the limited radius of the beam.

A similar spatial distribution of the electrostatic potential and the behavior of the beam were observed in the experiment and in numerical simulation [15]. The injection of an electron beam into the plasma in numerical simulation [15] leads under certain conditions to the DL formation.

So, DL is formed at a fast beam density, which takes values in a small interval near $n_{b} / n=1 / 4$. The considered DL moves with a velocity much less than the beam velocity. The DL width is comparable to the wavelength of the most unstable mode of beam instability. The perturbation of the ion density in the double-layer field is small.

It should be noted that the electron distribution function remains unstable. Indeed, in [15], excitation in the DL region of weak electron oscillations has been observed.

\section{VORTEX DYNAMICS}

The radial defocusing effect of the space charge of a decelerating beam and its collision with particles of partially ionized plasma lead to a gradual expansion of the decelerating beam. Thus, the reflected beam moves back on a larger radius, leading to a vortex-type dynamics Fig. 2.

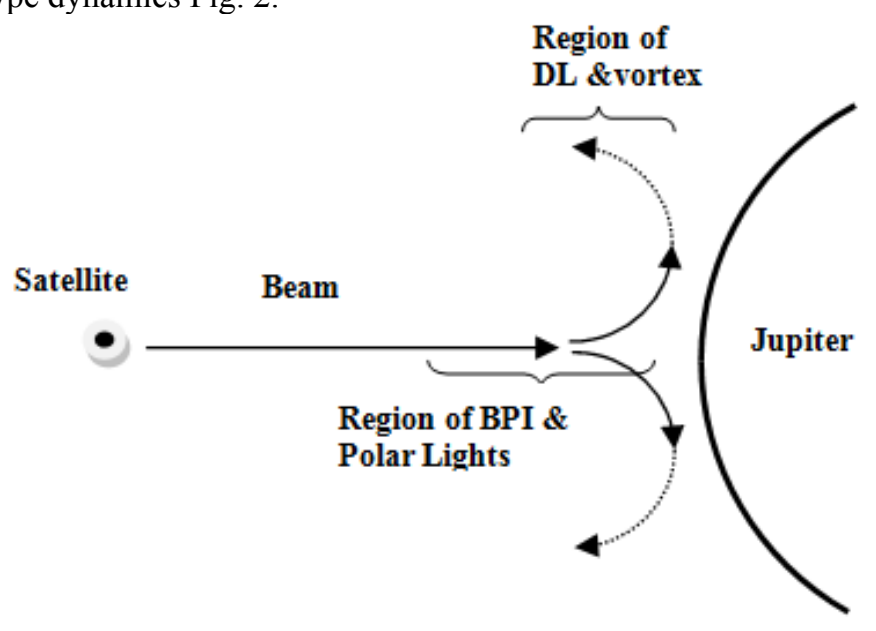

Fig. 2. A vortex dynamics of decelerating and reflected by double layer electron beam near Jupiter

\section{CONCLUSION}

So, the possible dynamics of the electron beam, formed in the vicinity of Io, the natural satellite of Jupiter, and injected toward Jupiter, has been investigated analytically. When a beam penetrates the Jupiter plasma to a certain depth, the beam-plasma instability can be developed. In this case, the distribution function of electrons is expanded additionally by excited oscillations. These electrons, when their energy is of order of a required certain value, cause UV polar light. For closing of a current, the formation of a double electric layer is necessary. The necessary parameters and conditions for the formation of a double layer with a large jump of an electric potential at a certain height have been formulated, its properties, stability, behavior over time and beam reflection in its field for closing of a current have been described. It has been shown that reflection of the beam can lead to its vortex dynamics.

To confirm the adequacy of the proposed model to the observed phenomena the electron distribution function in the vicinity of the region of reflection of high-energy electrons, both before and after the reflection area along the current tube should be measured in future observations. It is also necessary to measure the electron distribution function in the current tube in the interval between the natural satellite Io and Jupiter. 


\section{REFERENCES}

1. Gladstone G.R., Waite J.H., Grodent Jr,D. et al. A pulsating auroral X-ray hot spot on Jupiter // Letters to nature. NATURE. 2002. -Vol. 415. - P. 1000 - 1003.

2. Clarke J.T., Ajello J., Ballester G. et al. Ultraviolet emissions from the magnetic footprints of Io, Ganymede and Europa on Jupiter // Nature. - 2002. - Vol. 415. - P. 997-1000.

3. Connerney J.E.P. et al. Images of excited $\mathrm{H}_{3}^{+}$at the foot of the Io flux tube in Jupiter's atmosphere // Science. - 1993. -Vol. 262. - P. 1035-1038.

4. Clarke J.T. et al. Far-ultraviolet imaging of Jupiter's aurora and the Io "footprint" // Science. -1996. -Vol. 274. -P. 404-409.

5. Prangé R.et al. Rapid energy dissipation and variability of the Io-Jupiter electrodynamic circuit // Nature. - 1996. -Vol. 379. P. 323-325.

6. Goldreich P., Lynden-Bell D. Io, a Jovian unipolar inductor // Astrophys. J. - 1969. - Vol. 156. - P. 59-78.

7. Belcher J.W. The Jupiter-Io connection, an Alfven engine in space // Science. -1987. - Vol. 238. - P. $170-176$.

8. Neubauer F.M. Nonlinear standing Alfven wave current system at Io: theory // J. Geophys. Res. - 1980. - Vol. 85. P. 1171-1178.

9. Mauk B.H., Haggerty D.K., Paranicas C. et al. Discrete and broadband electron acceleration in Jupiter's powerful aurora // Nature. - 2017. - Vol. 549. - P. 66-69.

10. Dunn W.R., Branduardi-RaymontG., Ray L.C. et al. The independent pulsations of Jupiter's northern and southern X-ray auroras // Nature. Astronomy. - 2017. - Vol. 1. - P. 758-764.

11. Jacobsen S., Saur J., Neubauer F.M., Bonfond B., Gérard J.-C., Grodent D. Location and spatial shape of electron beams in Io's wake // Journal of Geophysical Research. - 2010. - Vol. 115. - P. A04205.

12. Fomin P.I., Fomina A.P., Mal'nev V.N. Superradiation of magnetized electrons and the power of decameter radiation of the Jupiter - IO system // Ukrayins'kij Fyizichnij Zhurnal. - 2004. - Vol. 49. - No.1. - P. 3-8.

13. Onishchenko I.N., Linetskii A.R., Matsiborko N.G., Shapiro V.D., Shevchenko V.I. Contribution to the Nonlinear Theory of Excitation of a Monochromatic Plasma Wave by an Electron Beam // ZhETF Pis'ma v Redaktsiiu. - 1970. - Vol. 12. - No.12. P. $407-411$.

14. Mikhailovsky A.B. Theory of plasma instabilities Vol. 1. - M.: Atomizdat, 1975. - P. 272.

15. Singh N., Schunk R.W. Plasma response to the injection of an electron beam // Plasma Phys. and Contr. Fus. - 1984. - Vol. 26. - No.7. - P. $359-390$.

16. Maslov V.I. Double layer formed by relativistic electron beam // Plasma Physics and Fusion Technology. - 1992. - Vol. 13. No.10. - P. 676-679.

17. Okuda H., Horton R., Ono M., Ashour-Abdalla M. Propagation of nonrelativistic electron beam in a plasma in a magnetic field // Phys. Fluids. - 1987. - Vol. 30. - No.1. - P. 200 - 203. 